Ольга Кулагина

ORCID: 0000-0002-7382-4751

Московский педагогический государственный университет

Москва, Россия

\title{
ЭЛЕМЕНТЫ ПРОПОВЕДИ В ТВОРЧЕСТВЕ ЖАКА ПРЕВЕРА
}

https://doi.org/10.34739/clit.2020.14.13

\section{ELEMENTS OF PREACHING IN JACQUES PRÉVERT'S WORKS}

Despite the fact that Jacques Prévert's ideas were explicitly anti-clerical, in his work there are some elements of preaching, since we interpret the sermon in a wide, not narrowly religious sense of the word. The author preaches the joy of life and a human attitude toward other (weaker) living creatures, which people traditionally consider as inferior. In this paper we will consider some elements of preaching in Prévert's poems and we will identify the main linguistic means of its transmission in the texts under analysis.

Keywords: preaching, Jacques Prévert, linguistic means

Несмотря на то, что термин «проповедь» изначально относится к религиозному дискурсу, вданной статье мы будем понимать проповедь в широком смысле - как распространение каких-либо учений, идей, взглядов, мнений${ }^{1}$. Действительно, для убеждённого антиклерикала, каковым был французский поэт Жак Превер, проповедь в своём религиозном значении была абсолютно чуждым жанром. И всё же, в широком понимании этого слова, в его творчестве она присутствует - как проповедь радости жизни и гуманного, уважительного отношения к тем, кто обычно оказывается в роли слабых и униженных. Подобная интерпретация

1 Толковый словарь Уиакова, https://dic.academic.ru/dic.nsf/ushakov/985530/ \%Do\%9F\%Do\%Ao\%Do\%9E\%Do\%9F\%Do\%9E\%Do\%92\%Do\%95\%Do\%94\%Do\%AC, [дата доступа: 20.12.2019]. 
проповеди вписывается в известную концепцию Р. Барта о том, что современный поэтический текст - это своего рода акт принуждения. ${ }^{2}$ В статье мы рассмотрим некоторые элементы проповеди в поэзии Жака Превера и выявим наиболее распространённые языковые средства, которые составляют проповеднический дискурс в его творчестве. В целом, в текстах Превера проповедь может приобретать самые различные формы. Так, например, это может быть проповедьпризыв, как в стихотворении Les enfants exigeants (Требовательные детu), где в роли адресата выступают родители, к которым дети обращаются со следующим требованием:
Pères
regardez-nous à gauche
regardez-nous à droite
Pères
regardez-nous dans la glace
et regardez-nous en face3.
Родители
посмотрите на нас слева
посмотрите на нас справа
Родители
посмотрите на нас в зеркале
и посмотрите нам в лицо4.

Стихотворение состоит из анафорических повторов обращения «Рѐres»(«Родители»), относящегося к возвышенному регистру5,и императива «regardez-nous» («посмотрите на нас»), призванных вызвать в старшем поколении отношение к детям как к личностям, с которыми следует взаимодействовать на равных.

Другой пример призыва, гораздо более эмоционального, мы можем наблюдать в стихотворении Le chemin de traverse (Путь наперерез):

\section{Traversez}

Traversez si le coeur vous en dit ou restez là plantés sur la plante de vos pieds

La Psyché s'en balance si le coeur vous en tait

\footnotetext{
${ }^{2}$ R. Barthes, Le degré zéro de l'écriture, suivi de Nouveaux essais critiques, Paris 2014, p. 41.

3 J. Prévert, Choses et autres, Paris 2011, p. 127.

4 Перевод наш - О.К.

5 https://www.larousse.fr/, [дата доступа: 14.12.2019].
} 
Traversez la plage de sable et de tain traversez l'horaire des marées traversez la douleur traversez le chagrin traversez l'écran traversez le documentaire ou la mer de Glace N'attendez pas la sonnette de l'entracte ou bien regardez-vous dans un iceberg ou dans un esquimau givré

il n'y a pas de quoi se mirer

Traversez l'armoire de votre mémoire

Le frigidaire noir traversez la mort Traversez traversez Et quand vous serez arrivés vous n'entendrez plus jamais les treize cris du miroitier dans les rues du bonheur brisé6.

Идите наперерез

Идите наперерез, если сердце вам так подсказывает, ну или так и стойте

твёрдо на ногах

Зеркалу плевать, что ваше сердце молчит Идите через насыпь из песка и амальгамы идите сквозь фазы приливов и отливов идите сквозь боль, идите сквозь горе идите сквозь экран идите сквозь документальный фильм и через Зеркально-ледяное море Не ждите звонка, возвещающего об антракте или же посмотрите на своё отражение в айсберге или в обледеневшем эскимо нечего смотреться Идите сквозь шкаф вашей памяти этот чёрный холодильник идите сквозь смерть Идите, идите наперерез И, когда вы наконец дойдёте, то уже никогда не услышите, как зеркальщик кричит тринадцать раз на улицах разбитого счастья7.

Мы снова можем наблюдать анафорический повтор императива, на этот раз глагола «traverse» - пересекать, идти

\footnotetext{
${ }^{6}$ J. Prévert, Soleil de nuit, Paris 2007, p. 231.

7 Перевод наш - О.К.
} 
наперерез. Этот глагол употребляется силлептически, как в прямом, так и в переносном значениях, показывая важность (с точки зрения автора) противостояния существующим правилам, которые только создают помехи на пути к счастью. Отдельно отметим обширное лексико-семантическое поле «зеркало»: «la Psyché» («зеркало»), «tain» («амальгама»), «la mer de Glace» («Зеркально-ледяное море»), «uniceberg» («айсберг»), «un esquimau givré» («обледеневшее эскимо»), «se mirer» («смотреться»), «le miroitier» («зеркальщик»), «brisé» («разбитое»). Оно представляется важным, т.к. зеркало, по мнению автора, также выступает в роли препятствия, вызывая рефлексию и заставляя человека сомневаться в правильности своих поступков. В связи с этим обращает на себя внимание последнее четверостишие, где парадоксальным образом сконцентрированы сразу три общеизвестных суеверия, создавая целую символическую действительность, обладающую собственными законами, отличными от законов действительности реальной ${ }^{8}$ с страх перед числом 13 , примета о разбитом зеркале и поверье о крике петуха, отгоняющем нечистую силу, причём разбитое зеркало метонимически символизирует разбитое счастье. Речь идёт, на наш взгляд, о призыве не поддаваться суевериям и идти им наперекор, чтобы наконец достичь своей цели.

Превер призывает также быть человечными по отношению к тем, кого мы традиционно привыкли считать низшими созданиями, хотя, по мнению поэта, они намного выше и благороднее людей. В качестве примера приведём стихотворение Tant pis (букв. «Тем хуже», но в русском переводе Михаила Яснова оно известно под названием «Впустите собаку»):

Faites entrer le chien couvert de boue

Tant pis pour ceux qui n'aiment ni les chiens ni la

Boue

Faites entrer le chien entièrement sali par la boue

Tant pis pour ceux qui n'aiment pas la boue

Qui ne comprennent pas

Qui ne savent pas le chien

Qui ne savent pas la boue

Faites entrer le chien

Et qu'il se secoue

${ }^{8}$ Г. Почепцов, Семиотика, Москва 2002, с. 38. 
On peut laver le chien

Et l'eau aussi on peut la laver

On ne peut pas laver ceux

Ceux qui disent qu'ils aiment les chiens

À condition que...

Le chien couvert de boue est propre

La boue est propre

L'eau est propre aussi quelquefois

Ceux qui disent à condition que...

Ceux-là ne sont pas propres

Absolument pas 9 .

Перевод М. Яснова:

Впустите скорее собаку, покрытую грязью,

Наплевать вам на тех, кто не любит собак и гнушается грязи,

Впустите, впустите собаку, которая вся,

От хвоста до загривка, заляпана грязью,

Наплевать вам на тех, кто гнушается грязи,

Кто не знает собак,

Не понимает собак

И не ведает грязи,

Впустите собаку,

Дайте ей отряхнуться от грязи,

Собаку можно отмыть,

Грязь можно отмыть,

Воду тоже можно отмыть,

Но никак не отмоешь того,

Кто твердит, что он любит собак

При одном лишь условии, что...

Нет, собака, покрытая грязью, чиста,

Грязь тоже чиста,

И даже вода

Иногда бывает чиста,

А те, кто твердит:

«При одном лишь условии, что...»-

Не бывают чисты

Никогда ${ }^{10}$.

В приведённом стихотворении основным способом воздействия на адресата снова является императив-«faites entrer le chien». В данном случае грамматическая составляющая

9 J. Prévert, Fatras, Paris 2007, p. 7.

10 https://www.askbooka.ru/stihi/zhak-prever/naplevat-vam-na-teh.html, [дата доступа: 25.12.19]. 
представляется важной, поскольку грамматика текста является существенным аспектом риторики ${ }^{11}$. Также обращает на себя внимание эпитет «propre» («чистый»), в составе парадоксов «Le chien couvert de boue est propre La boue est propre» («собака, покрытая грязью, чиста, грязь тоже чиста»),которые словно переворачивают привычную, обывательскую картину мира, где грязным собакам нет места в помещении для людей. Эллипсис «à condition que...» («при одном лишь условии, что...») дополняет этот эффект морального «перевёртыша», где уже не требуется уточнять, при каком условии человек всё же готов полюбить собак - одного этого эллипсиса достаточно, чтобы сделать вывод о том, что любовь в данном случае невозможна.

Другой пример призыва, не менее значимого с социальной точки зрения, мы встречаем в стихотворенииDéserteurs (Дезертиры):

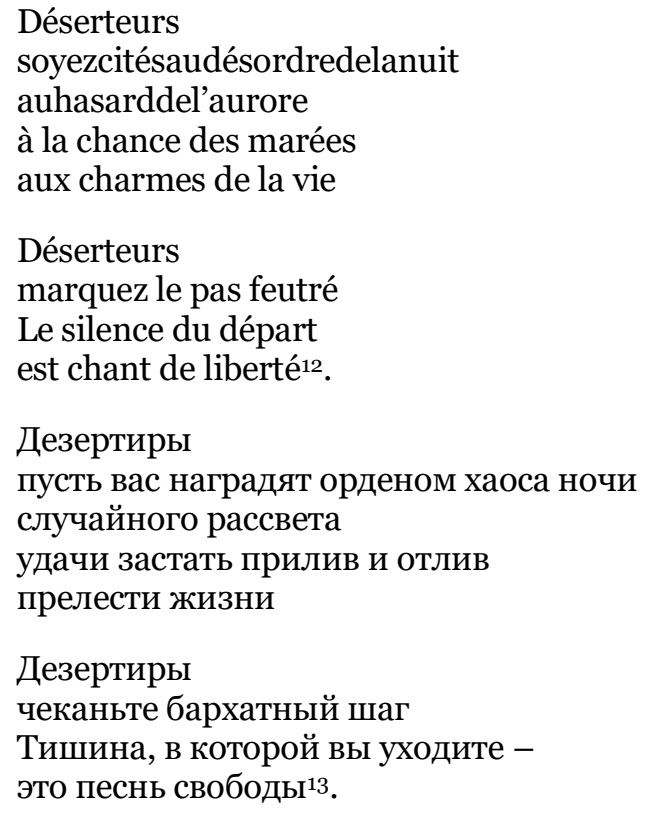

Приведённое стихотворение являет собой яркий пример антивоенной «проповеди». Военная лексика («cité»-«представленный

11 Ю. Лотман, Риторика, [в:] Статьи по семиотике и топологии культуры. https://www.gumer.info/bibliotek_Buks/Culture/Lotm/index.php, [дата доступа: 19.05.2020]. 12 J. Prévert, Choses..., op. cit., p. 138.

13 Перевод наш - О.К. 
к награде», «marquer le pas» - «чеканить шаг») сочетается с семантически противоположными ей лексемами («désordre» - «хаос», «hasard» - «случай», «chance» - «удача», «charmes» - «прелесть», «feutré» - «бархатный»), что в очередной раз создаёт эффект парадокса, где орден хаоса и случайности, полученный от самой природы за отказ убивать, оказывается более ценным, чем реальная военная награда, полученная за дисциплину и готовность выполнять любые приказы. Отметим также другой парадокс -«Le silence du départ est chant de liberté» («тишина, в которой вы уходите - это песнь свободы»), где антитеза «silence» - «chant» («тишина» - «песнь») образует единое целое, словно противопоставляя фанфары воинской славы и безвестность, в которую добровольно канет дезертир.

Встречаются у Превера и проповеди-пародии на настоящие назидания, в том числе с отсылкой к темам религии и загробного мира. В качестве примера приведём одно из его граффити: «Donnezvous la peine d'entrer dans le coma, mais ne mettez pas vos coudes sur le suaire»14 («Извольте впасть в кому, только не кладите локти на

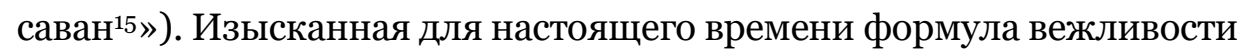
«donnez-vous la peine» («извольте») в данном контексте приобретает иронический оттенок и составляет очередной парадокс в сочетании с такими негативно окрашенными лексемами, как «сота» («кома») и «suaire» («саван»), а императив «ne mettez pas vos coudes sur le suaire» («не кладите локти на саван») только усиливает эффект иронии и абсурда, подчёркивая лицемерие современного общества, где можно быть в сколь угодно тяжёлом состоянии, но забывать о правилах приличия и шокировать окружающих - недопустимо, даже если человек находится на грани жизни и смерти.

Другая разновидность проповедей в творчестве Превера проповедь-пророчество, примером которой может служить следующее граффити: «Quand le vent noir du grand savoir / emportera la dernière plume du dernier oiseau / laTerre éclatera en sanglots» 16 («Когда чёрный ветер великого знания / унесёт последнее пёрышко последней птицы, / Земля разразится рыданиями» $\left.{ }^{17}\right)$. Нужно отметить, что птица - чрезвычайно важный персонаж во всём

\footnotetext{
14 J. Prévert, Fatras..., op. cit., p. 13.

15 Перевод наш - О.К.

${ }^{16}$ J. Prévert, Fatras..., op. cit., p. 192.

17 Перевод наш - О.К.
} 
творчестве Превера: это символ свободы, безмятежности, зачастую метафора любви. В данном примере птица со своей свободной натурой противопоставлена некоему знанию (по всей видимости, имеется в виду технический прогресс, развитие которого, так или иначе, отражается на состоянии живой природы), которое обозначается негативно окрашенной, макабрической метафорой «le vent noir» - «чёрный ветер». Гипербола «la dernière plume du dernier oiseau» - «последнее пёрышко последней птицы», а также гиперболическая персонификация «la Terre éclatera en sanglots»«Земля разразится рыданиями» показывают масштаб трагедии, к которой может привести уничтожение птиц вплоть до последнего пёрышка и всей живой природы в целом.

Приведём ещё один пример проповеди-пророчества в поэзии Превера:

Mangez sur l'herbe

Dépêchez-vous

Un jour ou l'autre

l'herbe mangera sur vous ${ }^{18}$.

Обедайте на траве

Спешите

Когда-нибудь

Трава будет обедать на вас ${ }^{19}$.

Здесь обращает на себя внимание эвфемизм l'herbe manger sur vous- трава будет обедать на вас, который показывает будущее, уготованное каждому человеку, но, пока оно не наступило, имеет смысл наслаждаться каждым моментом и не отказывать себе в простых радостях.

Также в творчестве Превера можно встретить проповедисентенции, например: «L'échelle humaine est un outil très approximatif et le plus laid des poux sur la tête du plus chauve des hommes, c'est quelqu'un ${ }^{20}$ («Человеческий масштаб - весьма относительный инструмент, и самая безобразная вошь на голове самого безволосого из людей уже чего-то стоит»²1). Двойная гипербола «le plus laid des

${ }^{18}$ J. Prévert, Fatras..., op. cit., p. 121.

19 Перевод наш - О.К.

${ }^{20}$ J. Prévert, Fatras..., op. cit., p. 85.

${ }^{21}$ Переводнаш - О.К. 
poux sur la tête du plus chauve des hommes» («самая безобразная вошь на голове самого безволосого из людей»)в сочетании с литотой «c'est quelqu'un»(«уже чего-то стоит») демонстрирует ценность каждого живого существа, вне зависимости от его внешней привлекательности и полезности для человека, который, по мнению Превера, отнюдь не является всеобщим мерилом.

Для наиболее полной иллюстрации особенностей проповеднического дискурса в творчестве Превера приведём ещё один пример сентенции из стихотворения $A \ldots$ (....):

Le Temps n'a pas de frontières

l'amour non plus

le Temps n'est pas raciste

le Temps est étoilé

l'amour est sang-mêlée2

Время не имеет границ

как и любовь

Время - не расист

Время раскрашено звездообразными пятнами

а любовь - полукровка²3.

В приведённом примере сочетаются метафоры и персонификации, которые призваны продемонстрировать всё разнообразие этого мира, в котором и заключается его прелесть. Уподобление времени некоему пятнистому животному, а любви сразу животному и человеку (т.к. лексема sang-mêlé может применяться как к животным, так и людям) подчёркивает красоту того, что люди, лишённые терпимости, называет несовершенством.

Подводя итог, подчеркнём, что в творчестве Жака Превера мы можем выделить такие виды проповеди в широком понимании данного термина, как проповедь-призыв, проповедь-пародия, проповедь-пророчество (или проповедь-предостережение), проповедь-сентенция. Основными посылами текстов Превера представляются необходимость толерантности и уважительного отношения к тем, кого люди привыкли считать низшими существами (в частности, к животным и детям), а также любовь к жизни и красота самых простых её моментов. Наиболее частотными лингвистическими средствами

${ }^{22}$ J. Prévert, Fatras..., op. cit., p. 281.

23 Перевод наш. - О.К. 
передачи этих идей являются антитезы, парадоксы, повторы, гиперболы, а также определённые лексико-семантические поля, наполненность которых представляется значимой в определённом контексте.

\section{Литература}

Аскбука литературы, https://www.askbooka.ru/stihi/zhak-prever/ naplevatvam-na-teh.html.

Лотман Ю., Риторика, [в:] Статьи по семиотике и топологии культуры. https://www.gumer.info/bibliotek_Buks/Culture/ Lotm/ index.php [дата доступа: 19.05.2020].

Почепцов Г., Семиотика, Москва 2002.

Толковый словарь Уиакова, https://dic.academic.ru/dic.nsf/ushakov/ 985530/\%Do\%9F\%Do\%Ao\%Do\%9E\%Do\%9F\%Do\%9E\%Do\%92\%D о\%95\%Do\%94\%Do\%АC [дата доступа: 15.12.2019]

Barthes R., Le degré zéro de l'écriture, suivi de Nouveaux essais critiques, Paris 2014.

Dictionnaire de français Larousse,https://www.larousse.fr/.

Prévert J., Choses et autres, Paris 2011.

Prévert J., Fatras, Paris 2007.

Prévert J., Soleil de nuit, Paris 2007.

\section{References}

Askbuka literatury, https://www.askbooka.ru/stihi/zhak-prever/naplevatvam-na-teh.html

Lotman Û., Ritorika, v: Stat'i po semiotike $i$ topologï kul'tury. https://www.gumer.info/bibliotek_Buks/Culture/Lotm/index.php[da ta dostupa: 19/05/2020]

Počepcov.G., Semiotika, Moskva 2002.

Tolkovyj Slovar' Ušakova, https://dic.academic.ru/dic.nsf/ushakov/ 985530/ \%Do\%9F\%Do\%Ao\%Do\%9E\%Do\%9F\%Do\%9E\%Do\%92\%Do\%95\%D 0\%94\%Do\%AC. [data dostupa: 15.12.2019]

Barthes R., Le degré zéro de l'écriture, suivi de Nouveaux essais critiques, Paris 2014.

Dictionnaire de français Larousse,https://www.larousse.fr/.

Prévert J., Choses et autres, Paris 2011.

Prévert J., Fatras, Paris 2007.

Prévert J., Soleil de nuit, Paris 2007. 